\title{
Effect of dietary factors on anaemia among rural elderly women in south-west China: a case-control study
}

\author{
Liping Meng ${ }^{1}$, Jun Liv ${ }^{2}$, Jian Zhang ${ }^{1, *}$, Chunrong Wang ${ }^{1}$, Qingqing Man ${ }^{1}$ and Lixiang $\mathrm{Li}^{1}$ \\ ${ }^{1}$ Institute of Nutrition and Food Safety, Chinese Center for Disease Control and Prevention, 29 Nanwei Road, \\ Xuanwu District, Beijing 100050, People's Republic of China: ${ }^{2}$ Guangxi Center for Disease Control and \\ Prevention, Nanning, Guangxi Province, People's Republic of China
}

Submitted 2 April 2008: Accepted 18 November 2008: First published online 23 January 2009

\begin{abstract}
Objective: To investigate the possible dietary risk factors for anaemia in rural elderly women.

Design: Case-control study conducted in 2005. Cases and matched controls were interviewed in person to elicit information on lifestyle, diet and individual health. Main foods and nutrients were calculated by three $24 \mathrm{~h}$ recalls; intake data of tea, edible oils and spices were from an FFQ.

Setting: Fourteen villages in two counties of Guangxi Province, south-west China. Subjects: Four hundred and twenty anaemic cases and 433 matched controls, aged 50-75 years.

Results: The mean consumption of animal foods for cases $(82.4 \mathrm{~g} / \mathrm{d})$ was significantly lower than for controls $(91 \cdot 0 \mathrm{~g} / \mathrm{d})$, similarly for egg consumption $(3 \cdot 8 \mathrm{~g} / \mathrm{d}$ for cases and $5.8 \mathrm{~g} / \mathrm{d}$ for controls; $P<0.05)$. The absolute value of the Dietary Balance Index, low bound score (DBI_LBS) was significantly higher for cases than for controls $(P<0 \cdot 05)$. Intakes of energy, protein, carbohydrate, vitamin A (retinol equivalents, RE), vitamin $\mathrm{B}_{1}$, riboflavin and Ca were significantly lower in cases than in controls $(P<0 \cdot 05)$. There was no significant difference in Fe intake between the two groups. High intake of vitamin A (RE) was inversely associated with anaemia (quartile $4 v$. quartile $1: \mathrm{OR}=0 \cdot 6, P$ for linear trend $=0 \cdot 02$ ). The absolute value of DBI_LBS was positively related to anaemia (quartile $4 v$. quartile 1: $\mathrm{OR}=0 \cdot 4, P$ for linear trend $<0 \cdot 0001)$.

Conclusion: For rural elderly women in south-west China, anaemia had a strong positive association with undernutrition and a negative association with vitamin A intake. Dietary Fe intake was not found to be an independent risk factor for anaemia.
\end{abstract}

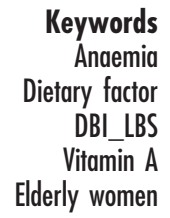

Keywords

Anaemia

DBI_LBS

Elderly women
Once considered as merely a disease marker, it is now appreciated that anaemia has profound implications as a risk factor for other illnesses while posing a serious health risk on its own. Anaemic patients have a shorter survival than their non-anaemic, age-matched counterparts ${ }^{(1)}$. Anaemia is also an independent risk factor for mortality in HIV infection ${ }^{(2)}$, cancer $^{(3)}$, renal disease ${ }^{(4)}$ and heart disease $^{(5)}$. Additionally, anaemia contributes to disease morbidity. Thus, anaemia constitutes a major health issue and no more so than in the elderly.

Anaemia is a common health problem among elderly populations worldwide, particularly in developing countries. The prevalence of anaemia in the elderly has been found to range from $8 \%$ to $44 \%$, with the highest prevalence in men aged 85 years and older ${ }^{(6-8)}$, by the WHO criteria for anaemia ( $\mathrm{Hb}$ of $<120 \mathrm{~g} / \mathrm{l}$ in women and $<130 \mathrm{~g} / 1 \mathrm{in} \mathrm{men})^{(9)}$. In China, the anaemia prevalence for people aged 60 years and older in rural areas was $31 \cdot 6 \%$, far higher than that in urban areas (19.6\%) and just second to that of infants, as reported by data of the Chinese Nutrition and Health Survey in $2002^{(10)}$. The dietary pattern has changed dramatically during the past 20 years in China, especially in rural China; however, the anaemia prevalence in rural China has changed little. Are there any special possible reasons behind the high prevalence of anaemia in rural Chinese elderly? Study shows that chronic blood loss from genitourinary tract cancer, chronic haemoptysis and bleeding disorders may result in Fe deficiency but are much less common causes ${ }^{(11)}$.

The aims of the present case-control study were to investigate the possible dietary risk factors for anaemia in rural elderly women in south-west China and also to provide basic data for further effective and sustainable preventive dietary measures for anaemia in the elderly population. 


\section{Subjects and methods}

\section{Study design}

The present population-based, case-control study was conducted in Guangxi Autonomous Region, south-west China. Study participants were peasants from fourteen villages in two counties of Guangxi Province, an area with a relative low economic income level. The study was approved by the ethics committee of the Nutrition and Food Safety Institute of the Chinese Center for Disease Control and Prevention (CDC).

\section{Study population}

All female volunteers, aged 50-75 years, gave a finger-prick blood sample for measurement of whole blood $\mathrm{Hb}$. Cases and controls were selected by their $\mathrm{Hb}$ value according to the anaemia criteria defined by WHO, $1968^{(9)}$.

1. Cases: Women with $\mathrm{Hb}$ concentration $<120 \mathrm{~g} / \mathrm{l}$ were identified as anaemic. Of the women with anaemia, those with serious diagnosed diseases were excluded, and those with $\mathrm{Hb}$ concentration between 90 and $120 \mathrm{~g} / 1$ became candidates for anaemia cases. Every candidate was sent a letter by a primary health-care physician, which described and explained the study and sought participation. If consent was obtained and a candidate wished to participate in the study, the primary health-care physician scheduled an appointment for an in-person interview.

2. Controls: The population-based controls were selected from the volunteers whose $\mathrm{Hb}$ concentration was $>130 \mathrm{~g} / \mathrm{l}$ and without serious diagnosed diseases. The controls were from the same village and were in the same age group ( 5 years to be considered as one group) as the cases. All controls were contacted in a fashion similar to the cases to schedule in-person interviews.

Each participant was requested to complete a health and lifestyle survey, a dietary survey and a basic health examination.

\section{Dietary data collection}

A Chinese FFQ and $24 \mathrm{~h}$ recall were used in dietary assessment. The FFQ comprised 108 food items grouped into sixteen categories and subjects were asked about their habitual diets at home during the past year. In addition, all of the foods the subjects ate within $24 \mathrm{~h}$ were recorded in a $24 \mathrm{~h}$ recall questionnaire, which was continued for three days. Food and nutrients were calculated from the three $24 \mathrm{~h}$ recalls, with a supplement for the intake of tea, edible oils and spices, which were not included in the $24 \mathrm{~h}$ recall questionnaire, by FFQ. All of the questionnaires were revised by specialist and validated by a pilot study. The whole dietary questionnaire was asked by trained interviewers. Food models were used to aid participants in estimating intake amounts in order to help improve data quality. To assess Fe intake accurately, the intake of mainly medicines, especially chalybeate, was also questioned. We assessed the dietary Fe intake according to results of the dietary survey and the Chinese food composition table ${ }^{(12)}$. More than $97 \%$ of the total Fe analysed in the diet came from the $24 \mathrm{~h}$ food recalls and the other $3 \%$ from the FFQ.

\section{Dietary Balance Index, low bound score}

To evaluate the relationship between the diet pattern and anaemia, we introduced the Chinese Dietary Balance Index (DBI) in which eight items - cereals, vegetables and fruits, beans and dairy, animal foods, alcohol, salt, edible oils and food variety - were chosen to assign cut-offs and point schemes based on the Chinese Food Guide Pagoda ${ }^{(13,14)}$. The maximal score was given for each component. If the consumption reached the recommended amount, score was 0 . The scores of the components reflecting underintake are negative, the ones reflecting over-intake are positive, and the ones which need to reflect both underand over-intake can be negative and positive. There are five methods to calculate DBI score: DBI total score (DBI_TS), DBI low bound score (DBI_LBS), DBI high bound score (DBI_HBS), DBI dietary quality distance (DBI_DQD) and DBI pattern. In the present paper, one of the scoring methods, DBI_LBS, was used to present the problem of under-intake and its severity. DBI_LBS is the sum of each negative score of all the related components. The higher the absolute value of DBI_LBS, the lower the food intake and the greater the severity of undernutrition. Four of the eight items - i.e. cereals, vegetables and fruits, beans and dairy, animal food, whose scores can be negative - were selected to calculate DBI_LBS. Table 1 shows the four selected DBI components and their method of evaluation.

\section{Lifestyle survey and basic bealth examination}

Each participant was interviewed at the time of enrolment to obtain information on health status and lifestyle including demographic data, education, marriage, expenditure on food, physical activity, exercise, smoking and alcohol, suffering chronic disease and which kind of chronic disease diagnosed at hospital (eleven kinds of chronic disease which might relate to anaemia were considered, including alimentary tract ulcer, haemorrhoids and lung tuberculosis), sleeping and mood. A simple health examination comprising measurement of weight, height, waist circumference, heart rate and blood pressure was done for each participant. Anthropometry was performed by trained examiners following a standardized protocol.

\section{Data analysis}

Data processing and statistical analyses were done using the Epi Info (Centers for Disease Control and Prevention, Atlanta, GA, USA) and SAS 8.2 software packages (SAS Institute, Inc., Cary, NC, USA). The $t$ test and the $\chi^{2}$ test were 
used to compare continuous variables and frequencies, respectively, between the two groups. We calculated odds ratios and 95\% confidence intervals from unconditional logistic regression models to ascertain the association of total energy and nutrient intakes (in quartiles) with anaemia risk. Cut-off points for quartiles of nutrient intakes were determined on the basis of distributions among all controls. Total meat consumption, protein, age, BMI, waist circumference (WC), diastolic blood pressure (DBP) and systolic blood pressure (SBP) were evaluated as potential confounding factors in model I. Furthermore, energy, fat, expenditure on food and pregnancy times in lifetime were adjusted in model II on the basis of model I. Each nutrient had a unique set of confounding variables. A stepwise procedure was performed to obtain the final model. Statistical tests were two-sided. Significance was set at $P<0 \cdot 05$.

\section{Results}

\section{General characteristics of the subjects}

The finger blood $\mathrm{Hb}$ level was detected for a total of 1696 rural women aged 50-75 years in Guangxi Chuang Autonomous Region. Of the 492 women diagnosed with anaemia, eighteen had $\mathrm{Hb}$ concentration $<90 \mathrm{~g} / \mathrm{l}$ and 474 had $\mathrm{Hb}$ concentration between 90 and $120 \mathrm{~g} / \mathrm{l}$. Due to nine women refusing, eleven being untraceable and thirteen dropping out because of illness, 441 candidates with $\mathrm{Hb}$ between 90 and $120 \mathrm{~g} / \mathrm{l}$ were finally selected as cases and thus the response rate (interviewed/eligible) was $93.0 \%$. Four hundred and thirty-nine of the 480 eligible candidates $(\mathrm{Hb}>120 \mathrm{~g} / \mathrm{dl})$ were selected as controls and the response rate was $91.5 \%$ (twenty-four women refused, nine were untraceable and eight dropped out because of illness). After being checked according to designated criteria, twenty-one cases and six controls with unreasonable dietary information were deleted during the process of data analysis. Thus, data of 420 cases and 433 controls were used for the final analysis.

The average $\mathrm{Hb}$ concentration in the anaemia group was $112 \cdot 0 \mathrm{~g} / \mathrm{l}$, ranging from $90 \cdot 0$ to $119 \cdot 9 \mathrm{~g} / \mathrm{l}$; while the average $\mathrm{Hb}$ concentration in controls was $138.5 \mathrm{~g} / \mathrm{l}$ and ranged from $125 \cdot 9$ to $173 \cdot 0 \mathrm{~g} / \mathrm{l}$.

The proportion of ethnic minority Chuang and pregnancy times in lifetime were significantly higher in cases than in controls $(P=0.03$ for both). BMI $(P<0.001)$, WC $(P<0 \cdot 001)$, DBP $(P=0 \cdot 005)$ and expenditure on food $(P=0.004)$ were significantly lower in cases compared with controls. No significantly difference was observed for SBP and heart rate between the two groups (Table 2).

\section{Dietary assessment}

Table 3 shows the mean daily food consumption and nutrient intakes. The mean consumption of animal foods in controls was $91.0 \mathrm{~g} / \mathrm{d}, 10.5 \%$ higher than that in cases. 
Table 2 Descriptive characteristics of participants with and without anaemia ( $n$ 853): rural elderly women aged $50-75$ years, Guangxi Province, south-west China, 2005

\begin{tabular}{|c|c|c|c|c|c|c|c|}
\hline \multirow[b]{2}{*}{ Participant characteristic } & \multicolumn{3}{|c|}{ Controls ( $n$ 433) } & \multicolumn{3}{|c|}{ Cases $(n$ 420) } & \multirow[b]{2}{*}{$P$} \\
\hline & Mean & SD & $\%$ & Mean & SD & $\%$ & \\
\hline Age (years) & $58 \cdot 8$ & $7 \cdot 8$ & & $61 \cdot 0$ & $8 \cdot 1$ & & $<0.001$ \\
\hline $\mathrm{Hb}(\mathrm{g} / \mathrm{l})$ & $138 \cdot 5$ & $7 \cdot 3$ & & $112 \cdot 0$ & $6 \cdot 2$ & & 0.01 \\
\hline Chuang ethnic minority & & & $89 \cdot 8$ & & & $94 \cdot 2$ & 0.03 \\
\hline Under elementary school education & & & $86 \cdot 4$ & & & $90 \cdot 1$ & $0 \cdot 10$ \\
\hline Body weight $(\mathrm{kg})$ & $46 \cdot 70$ & $8 \cdot 12$ & & $44 \cdot 19$ & $6 \cdot 46$ & & $<0.001$ \\
\hline BMI $\left(\mathrm{kg} / \mathrm{m}^{2}\right)$ & $20 \cdot 8$ & $2 \cdot 9$ & & $19 \cdot 9$ & $2 \cdot 4$ & & $<0.001$ \\
\hline Waist circumference $(\mathrm{cm})$ & $71 \cdot 0$ & $8 \cdot 1$ & & $68 \cdot 6$ & $7 \cdot 0$ & & $<0.001$ \\
\hline Diastolic blood pressure (mmHg) & $77 \cdot 8$ & $11 \cdot 8$ & & $75 \cdot 5$ & $12 \cdot 3$ & & 0.005 \\
\hline Systolic blood pressure (mmHg) & $122 \cdot 6$ & $20 \cdot 4$ & & $122 \cdot 4$ & $19 \cdot 5$ & & 0.98 \\
\hline Expenditure on food (yuan, RMB) & $73 \cdot 4$ & $74 \cdot 5$ & & $59 \cdot 5$ & $67 \cdot 2$ & & 0.004 \\
\hline Usual resting and sleeping time per day $(\mathrm{h})$ & $11 \cdot 2$ & $2 \cdot 4$ & & $11 \cdot 4$ & $2 \cdot 3$ & & $0 \cdot 22$ \\
\hline Usual working time per day $(\mathrm{h})$ & $9 \cdot 1$ & $2 \cdot 8$ & & $9 \cdot 0$ & $2 \cdot 6$ & & $0 \cdot 68$ \\
\hline Pregnancy times in lifetime & $4 \cdot 2$ & $2 \cdot 1$ & & $4 \cdot 7$ & $3 \cdot 6$ & & 0.03 \\
\hline Working hours in busy farming season (h) & $6 \cdot 4$ & $2 \cdot 7$ & & $6 \cdot 4$ & $2 \cdot 7$ & & 0.99 \\
\hline Working hours in slack farming season (h) & $3 \cdot 6$ & $1 \cdot 9$ & & $3 \cdot 8$ & $2 \cdot 7$ & & $0 \cdot 25$ \\
\hline Proportion having physical exercise & & & 0.5 & & & $0 \cdot 2$ & 0.55 \\
\hline Proportion smoking & & & $3 \cdot 4$ & & & $1 \cdot 7$ & $0 \cdot 11$ \\
\hline Proportion passive smoking & & & $31 \cdot 6$ & & & $30 \cdot 3$ & $0 \cdot 82$ \\
\hline Proportion experiencing severe food scarcity & & & $24 \cdot 3$ & & & $26 \cdot 3$ & 0.38 \\
\hline Proportion drinking wine & & & $23 \cdot 6$ & & & $20 \cdot 8$ & $0 \cdot 41$ \\
\hline
\end{tabular}

The consumption of total animal foods $(P=0 \cdot 04)$, eggs $(P=0 \cdot 04)$, staple foods $(P=0 \cdot 002)$ and vegetables $(P=0 \cdot 01)$ was significantly lower in cases than in controls. The poultry consumption of controls was $30 \%$ higher than that of cases but without statistical difference, similarly for the consumption of red meat and aquatic products. However, the absolute value of DBI_LBS was significantly higher in cases than in controls $(P<0 \cdot 0001)$.

Energy $(P=0 \cdot 02)$, protein $(P=0 \cdot 008)$, carbohydrate $(P<0 \cdot 0001)$, vitamin A (retinol equivalents, RE; $P=$ $0 \cdot 04)$, vitamin $\mathrm{B}_{1}(P=0 \cdot 01)$, riboflavin $(P=0 \cdot 01)$ and Ca $(P=0 \cdot 04)$ intakes in cases were significantly lower than in controls. There was no significant difference in food sources of both dietary Fe and dietary protein between the cases and controls. Vegetables, staple foods and animal foods were the main sources of dietary Fe for the two groups, and also staple foods and animal foods were the main sources of protein for both groups.

\section{Relationship between dietary pattern, nutrients and anaemia}

Table 4 shows the associations (odds ratios and 95\% confidence intervals) of DBI_LBS and nutrients with anaemia. The absolute value of DBI_LBS was positively related to anaemia in both model I and model II (quartile $4 v$. quartile 1 : $\mathrm{OR}=0 \cdot 4, P$ for linear trend $<0 \cdot 0001)$. High intake of vitamin A (RE) was inversely associated with anaemia in both model I and model II (quartile $4 v$. quartile $1: \mathrm{OR}=0 \cdot 6, P$ for linear trend $=0 \cdot 02$ ). However, other nutrients, such as total energy, protein, fat, carbohydrate, vitamin $\mathrm{A}(\mu \mathrm{g}), \beta$-carotene, vitamin $\mathrm{B}_{1}$, riboflavin, vitamin $\mathrm{C}, \mathrm{Ca}$ and $\mathrm{Fe}$, were not associated with anaemia in either model I or model II.

\section{Discussion}

\section{Vitamin A (RE) intake and its relationship with anaemia}

The present research showed that vitamin A (RE) intakes in cases and controls were quite low, about $60 \%$ of the recommended amount of $700 \mu \mathrm{g} \mathrm{RE} / \mathrm{d}$ for Chinese elderly women. As to the source, about $90 \%$ of vitamin A (RE) was from $\beta$-carotene. The results also showed that vitamin A (RE) was significantly negatively related to anaemia (quartile $4 v$. quartile $1: \mathrm{OR}=0 \cdot 6, P=0 \cdot 02$ ), indicting that poor vitamin A (RE) status contributes to low Fe bioavailability. A previous study showed that vitamin A deficiency was an independent risk factor for anaemia in children $(\mathrm{OR}=4 \cdot 85,95 \% \text { CI } 2 \cdot 14,10 \cdot 9, P<0 \cdot 0001)^{(15)}$. In another study, with decreasing serum vitamin A concentration, the prevalence and severity of anaemia increased in Chinese children ${ }^{(16)}$. A similar result was also found among pregnant women in the plains of $\mathrm{Nepal}^{(17)}$. There are many potential biological mechanisms by which vitamin A deficiency could cause anaemia. These mechanisms fall into three general categories: (i) modulation of erythropoiesis; (ii) modulation of immunity to infectious diseases and the anaemia of infection; and (iii) modulation of Fe metabolism. There is probably some overlap between these mechanisms, as erythropoiesis and Fe metabolism are modulated by infection ${ }^{(18)}$. Although vitamin A deficiency is a cause of anaemia, further work is needed to characterize both the pathogenesis and the public health importance of 'vitamin A deficiency anaemia'. Furthermore, consideration should be given to communitybased trials of multi-micronutrient supplementation as a strategy to reduce anaemia in both children and women in developing countries. 
Table 3 Food consumption, nutrient intakes, and food sources of dietary iron and dietary protein among participants with and without anaemia ( $n$ 853): rural elderly women aged 50-75 years, Guangxi Province, south-west China, 2005

\begin{tabular}{|c|c|c|c|c|c|c|c|}
\hline & \multicolumn{2}{|c|}{ Overall ( $n$ 853) } & \multicolumn{2}{|c|}{ Controls ( $n$ 433) } & \multicolumn{2}{|c|}{ Cases $(n$ 420) } & \multirow[b]{2}{*}{$P^{*}$} \\
\hline & Mean & SD & Mean & SD & Mean & SD & \\
\hline \multicolumn{8}{|l|}{ Food consumption } \\
\hline Animal foods (g/d) & $86 \cdot 6$ & $61 \cdot 2$ & $91 \cdot 0$ & $62 \cdot 0$ & $82 \cdot 4$ & $60 \cdot 2$ & 0.04 \\
\hline Red meat $(\mathrm{g} / \mathrm{d})$ & $73 \cdot 4$ & $53 \cdot 7$ & $75 \cdot 6$ & $53 \cdot 0$ & $71 \cdot 3$ & $54 \cdot 4$ & $0 \cdot 24$ \\
\hline Poultry (g/d) & $6 \cdot 2$ & $20 \cdot 2$ & $7 \cdot 1$ & $21 \cdot 0$ & $5 \cdot 4$ & $19 \cdot 4$ & $0 \cdot 24$ \\
\hline Aquatic products (g/d) & $2 \cdot 2$ & $10 \cdot 8$ & $2 \cdot 6$ & $12 \cdot 1$ & $1 \cdot 9$ & $9 \cdot 4$ & $0 \cdot 39$ \\
\hline Eggs $(g / d)$ & $4 \cdot 8$ & $14 \cdot 1$ & $5 \cdot 8$ & $15 \cdot 5$ & $3 \cdot 8$ & $12 \cdot 5$ & 0.04 \\
\hline Staple foods (g/day) $\dagger$ & $279 \cdot 5$ & $71 \cdot 8$ & $287 \cdot 2$ & $68 \cdot 8$ & $272 \cdot 0$ & $73 \cdot 9$ & 0.002 \\
\hline Nuts (g/day) & 0.4 & $4 \cdot 7$ & $0 \cdot 2$ & $2 \cdot 4$ & $0 \cdot 7$ & $6 \cdot 1$ & $0 \cdot 16$ \\
\hline Soyabeans and products $(\mathrm{g} / \mathrm{d}) \ddagger$ & $10 \cdot 3$ & $17 \cdot 5$ & $10 \cdot 3$ & $17 \cdot 8$ & $10 \cdot 2$ & $17 \cdot 2$ & 0.93 \\
\hline Vegetables $(g / d) \S$ & $281 \cdot 2$ & $96 \cdot 5$ & $289 \cdot 7$ & $91 \cdot 7$ & $273 \cdot 0$ & $100 \cdot 3$ & 0.01 \\
\hline Fruits $(g / d)$ & 0.5 & $4 \cdot 6$ & 0.5 & 4.9 & 0.5 & $4 \cdot 4$ & 0.95 \\
\hline Wine $(g / d) \|$ & $6 \cdot 4$ & $22 \cdot 7$ & $6 \cdot 5$ & $19 \cdot 9$ & $6 \cdot 3$ & $25 \cdot 2$ & $0 \cdot 89$ \\
\hline Edible oils $(\mathrm{g} / \mathrm{d})$ & $29 \cdot 5$ & $10 \cdot 8$ & $28 \cdot 8$ & $13 \cdot 8$ & $30 \cdot 2$ & $22 \cdot 6$ & $0 \cdot 26$ \\
\hline Condiments (g/d) & $9 \cdot 5$ & $5 \cdot 5$ & $9 \cdot 2$ & $4 \cdot 8$ & $9 \cdot 8$ & $6 \cdot 2$ & 0.09 \\
\hline DBI_LBS & $-28 \cdot 2$ & $3 \cdot 7$ & $-27 \cdot 6$ & $3 \cdot 4$ & $-28 \cdot 7$ & $3 \cdot 9$ & $<0.0001$ \\
\hline \multicolumn{8}{|l|}{ Nutrient intakes } \\
\hline Energy (kJ) & 6495 & 1811 & 6643 & 1637 & 6353 & 1955 & 0.02 \\
\hline Energy (kcal) & $1552 \cdot 3$ & $432 \cdot 8$ & $1587 \cdot 6$ & $391 \cdot 2$ & $1518 \cdot 4$ & $467 \cdot 2$ & 0.02 \\
\hline Protein (g) & $41 \cdot 9$ & $13 \cdot 6$ & $43 \cdot 1$ & $13 \cdot 7$ & $40 \cdot 7$ & $13 \cdot 4$ & 0.008 \\
\hline Fat (g) & $59 \cdot 8$ & $27 \cdot 1$ & $60 \cdot 4$ & $24 \cdot 2$ & $59 \cdot 1$ & $29 \cdot 7$ & 0.48 \\
\hline Dietary fibre $(\mathrm{g})$ & $6 \cdot 4$ & $4 \cdot 6$ & $6 \cdot 5$ & $4 \cdot 5$ & $6 \cdot 2$ & $4 \cdot 6$ & 0.47 \\
\hline Carbohydrate (g) & $214 \cdot 8$ & $60 \cdot 9$ & $220 \cdot 9$ & $57 \cdot 1$ & $208 \cdot 9$ & $63 \cdot 9$ & $<0.0001$ \\
\hline Vitamin A ( $\mu \mathrm{g}$ RE) & $432 \cdot 9$ & $343 \cdot 0$ & $458 \cdot 2$ & $348 \cdot 9$ & $408 \cdot 7$ & $335 \cdot 9$ & 0.04 \\
\hline$\beta$-Carotene $(\mu \mathrm{g})$ & $2073 \cdot 0$ & $1329 \cdot 1$ & $2148 \cdot 6$ & $1302 \cdot 7$ & $2000 \cdot 4$ & $1351 \cdot 5$ & $0 \cdot 10$ \\
\hline Vitamin $A(\mu \mathrm{g})^{\star \star}$ & $158 \cdot 2$ & $301 \cdot 2$ & $173 \cdot 7$ & $314 \cdot 0$ & $143 \cdot 3$ & $288 \cdot 0$ & $0 \cdot 14$ \\
\hline Vitamin $B_{1}(\mathrm{mg})$ & $0 \cdot 70$ & 0.2 & $0 \cdot 72$ & $0 \cdot 22$ & 0.69 & 0.23 & 0.03 \\
\hline Riboflavin (mg) & 0.48 & $0 \cdot 2$ & 0.50 & 0.23 & 0.46 & $0 \cdot 22$ & 0.01 \\
\hline Vitamin C (mg) & $100 \cdot 5$ & $45 \cdot 3$ & $103 \cdot 2$ & $42 \cdot 8$ & $97 \cdot 9$ & $47 \cdot 4$ & 0.09 \\
\hline Vitamin E (mg) & $7 \cdot 3$ & $4 \cdot 8$ & $7 \cdot 4$ & $4 \cdot 7$ & $7 \cdot 2$ & $4 \cdot 9$ & 0.44 \\
\hline $\mathrm{Ca}(\mathrm{mg})$ & $229 \cdot 7$ & $81 \cdot 0$ & $235 \cdot 5$ & $77 \cdot 8$ & $224 \cdot 2$ & $83 \cdot 8$ & 0.04 \\
\hline \multirow[t]{2}{*}{$\mathrm{Fe}(\mathrm{mg})$} & $10 \cdot 2$ & $12 \cdot 9$ & $10 \cdot 9$ & $13 \cdot 6$ & $9 \cdot 5$ & $12 \cdot 1$ & $0 \cdot 11$ \\
\hline & \multicolumn{2}{|c|}{$\%$} & \multicolumn{2}{|c|}{$\%$} & \multicolumn{2}{|c|}{$\%$} & \\
\hline \multicolumn{8}{|l|}{ Food sources of dietary $\mathrm{Fe}$} \\
\hline Animal foods & \multicolumn{2}{|c|}{$22 \cdot 0$} & \multicolumn{2}{|c|}{$22 \cdot 7$} & \multicolumn{2}{|c|}{$21 \cdot 3$} & $0 \cdot 30$ \\
\hline Staple foods & \multicolumn{2}{|c|}{$33 \cdot 3$} & \multicolumn{2}{|c|}{$34 \cdot 4$} & \multicolumn{2}{|c|}{$33 \cdot 2$} & $0 \cdot 87$ \\
\hline Vegetables & \multicolumn{2}{|c|}{$33 \cdot 4$} & \multicolumn{2}{|c|}{$33 \cdot 1$} & \multicolumn{2}{|c|}{$33 \cdot 7$} & $0 \cdot 62$ \\
\hline Soyabeans and products & \multirow{2}{*}{\multicolumn{2}{|c|}{$\begin{array}{l}7 \cdot 9 \\
3 \cdot 4\end{array}$}} & \multicolumn{2}{|c|}{$7 \cdot 6$} & \multicolumn{2}{|c|}{$8 \cdot 3$} & $0 \cdot 42$ \\
\hline Other foods & & & & & & & 0.27 \\
\hline Food sources of dietary protein & & & & & & & \\
\hline Animal foods & & & & & & & 0.09 \\
\hline Staple foods & & & & & & & $0 \cdot 78$ \\
\hline Soyabeans and products & & & & & & & $0 \cdot 30$ \\
\hline Other foods & & & & & & & 0.06 \\
\hline
\end{tabular}

DBI_LBS, Dietary Balance Index, low bound score.

*The $t$ test (for food consumption and nutrient intakes) and the $\chi^{2}$ test (for food sources of dietary Fe and food sources of dietary protein) were used to test for differences between cases and controls.

tIncluding mung beans, red beans and long-grained rice.

$\ddagger$ Soyabean products amount to soyabeans to calculate the quantity.

§Besides general vegetables, including fungi, algae, potatoes and dry legumes except mung beans, red beans and long-grained rice.

IIWine was converted to alcohol content.

TMicrograms of retinol equivalents, the sum of vitamin A intake from animal foods and $\beta$-carotene from plant sources.

${ }^{*}$ Vitamin A from animal foods.

\section{DBI_LBS and its relationship with anaemia}

The DBI was established based on the Dietary Guideline for Chinese Residents, as was the ideal value corresponding to score of 0 for each DBI component. The different methods of calculating DBI score reflect different dietary problems. For example, DBI_HBS, the sum of each positive score of each related component, is used to present over-intake and its severity. DBI_LBS, the sum of each negative score of each related component, is used to assess under-intake and its severity. The nearer the DBI_LBS is to zero, the slighter the dietary under-intake. The higher the absolute value of DBI_LBS, the greater the severity of the dietary under-intake ${ }^{(13)}$. The absolute value of DBI_LBS was positively related to anaemia in the present study, indicating that under-intake or undernutrition is a risk factor for anaemia. Actually, the region included in the study was relatively poor in rural China. Most subjects do not have adequate food consumption as 
Table 4 Associations of DBI_LBS and nutrients with anaemia: rural elderly women aged 50-75 years, Guangxi Province, south-west China, 2005

\begin{tabular}{|c|c|c|c|c|c|c|}
\hline \multirow[b]{2}{*}{ Item $^{*}$} & \multirow[b]{2}{*}{ No. of cases } & \multirow[b]{2}{*}{ Median daily intake in controls } & \multicolumn{2}{|c|}{ Model It } & \multicolumn{2}{|c|}{ Model II¥ } \\
\hline & & & OR & $95 \% \mathrm{Cl}$ & OR & $95 \% \mathrm{Cl}$ \\
\hline \multicolumn{7}{|l|}{ DBI_LBS } \\
\hline Q1§ (referent) & 121 & -32 & $1 \cdot 0$ & & $1 \cdot 0$ & \\
\hline Q2§ & 92 & -29 & $1 \cdot 0$ & $0 \cdot 6,1 \cdot 5$ & $1 \cdot 0$ & $0 \cdot 7,1 \cdot 6$ \\
\hline Q3\$ & 138 & -27 & 0.6 & $0.4,0.9$ & 0.6 & $0.4,0.9$ \\
\hline Q4§ & 69 & -24 & $0 \cdot 4$ & $0 \cdot 3,0 \cdot 7$ & 0.4 & $0.3,0.7$ \\
\hline$P$ for linear trend & & & \multicolumn{2}{|c|}{$<0.0001$} & \multicolumn{2}{|c|}{$<0.0001$} \\
\hline \multicolumn{7}{|c|}{ Total energy (kJ/kcal) } \\
\hline Q1 (referent) & 142 & $4810 / 1149 \cdot 5$ & $1 \cdot 0$ & & $1 \cdot 0$ & \\
\hline Q2 & 79 & $6064 / 1449 \cdot 3$ & 0.6 & $0.4,0.9$ & 0.6 & $0.4,0.9$ \\
\hline Q3 & 92 & $7037 / 1681 \cdot 9$ & 0.7 & $0 \cdot 5,1 \cdot 1$ & 0.7 & $0.5,1 \cdot 0$ \\
\hline Q4 & 107 & $8384 / 2003 \cdot 8$ & 0.8 & $0 \cdot 6,1 \cdot 2$ & 0.8 & $0 \cdot 6,1 \cdot 2$ \\
\hline$P$ for linear trend & & & \multicolumn{2}{|c|}{0.09} & \multicolumn{2}{|c|}{$0 \cdot 12$} \\
\hline \multicolumn{7}{|l|}{ Protein (g) } \\
\hline Q1 (referent) & 137 & $29 \cdot 0$ & $1 \cdot 0$ & & $1 \cdot 0$ & \\
\hline Q2 & 75 & $37 \cdot 6$ & $1 \cdot 3$ & $0 \cdot 8,2 \cdot 1$ & $1 \cdot 2$ & $0 \cdot 8,2 \cdot 0$ \\
\hline Q3 & 120 & $45 \cdot 5$ & $1 \cdot 1$ & $0 \cdot 7,1 \cdot 8$ & $1 \cdot \overline{2}$ & $0 \cdot 7,1 \cdot 8$ \\
\hline Q4 & 88 & $58 \cdot 1$ & 0.8 & $0 \cdot 6,1 \cdot 2$ & $0 \cdot 8$ & $0 \cdot 6,1 \cdot 2$ \\
\hline$P$ for linear trend & & & & & & \\
\hline Fat $(g)$ & & & & & & \\
\hline Q1 (referent) & 135 & $35 \cdot 5$ & $1 \cdot 0$ & & $1 \cdot 0$ & \\
\hline Q2 & 86 & $50 \cdot 2$ & 0.7 & $0 \cdot 4,1 \cdot 1$ & 0.7 & $0 \cdot 4,1 \cdot 1$ \\
\hline Q3 & 82 & $65 \cdot 3$ & 0.9 & $0 \cdot 6,1 \cdot 3$ & 0.8 & $0 \cdot 6,1 \cdot 3$ \\
\hline Q4 & 117 & $86 \cdot 5$ & $1 \cdot 0$ & $0 \cdot 7,1 \cdot 4$ & $1 \cdot 0$ & $0 \cdot 7,1 \cdot 4$ \\
\hline$P$ for linear trend & & & & & & \\
\hline Carbohydrate (g) & & & & & & \\
\hline Q1 (referent) & 135 & $154 \cdot 9$ & $1 \cdot 0$ & & $1 \cdot 0$ & \\
\hline Q2 & 91 & $198 \cdot 2$ & 0.5 & $0.3,0.8$ & 0.5 & $0.3,0.9$ \\
\hline Q3 & 99 & $241 \cdot 6$ & $1 \cdot 3$ & $0 \cdot 9,2 \cdot 0$ & $1 \cdot 3$ & $0 \cdot 9,2 \cdot 0$ \\
\hline Q4 & 95 & $280 \cdot 5$ & 0.8 & $0 \cdot 6,1 \cdot 1$ & 0.8 & $0 \cdot 6,1 \cdot 1$ \\
\hline$P$ for linear trend & & & & & & \\
\hline Vitamin A ( $\mu \mathrm{g} R \mathrm{R}$ & & & & & & \\
\hline Q1 (referent) & 142 & $162 \cdot 9$ & $1 \cdot 0$ & & $1 \cdot 0$ & \\
\hline Q2 & 106 & 289.5 & 0.8 & $0 \cdot 5,1 \cdot 1$ & 0.8 & $0.5,1 \cdot 1$ \\
\hline Q3 & 95 & $481 \cdot 6$ & 0.8 & $0 \cdot 5,1 \cdot 2$ & $0 \cdot 8$ & $0.5,1.1$ \\
\hline Q4 & 77 & $732 \cdot 1$ & 0.6 & $0.4,0.8$ & 0.6 & $0.4,0.9$ \\
\hline$P$ for linear trend & & & & & & \\
\hline$\beta$-Carotene $(\mu \mathrm{g})$ & & & & & & \\
\hline Q1 (referent) & 140 & $767 \cdot 7$ & $1 \cdot 0$ & & $1 \cdot 0$ & \\
\hline Q2 & 85 & $1406 \cdot 4$ & 0.6 & $0.4,0.9$ & 0.6 & $0.4,0.9$ \\
\hline Q3 & 103 & $2475 \cdot 4$ & 0.8 & $0.5,1.0$ & 0.7 & $0.5,1.0$ \\
\hline Q4 & 91 & $3724 \cdot 7$ & 0.8 & $0 \cdot 5,1 \cdot 0$ & 0.7 & $0.5,1.0$ \\
\hline$P$ for linear trend & & & & & & \\
\hline Vitamin $A(\mu \mathrm{g})^{\top}$ & & & & & & \\
\hline Q1 (referent) & 146 & $42 \cdot 5$ & $1 \cdot 0$ & & $1 \cdot 0$ & \\
\hline Q2 & 91 & $78 \cdot 3$ & 0.6 & $0.4,0.9$ & 0.6 & $0.4,0.9$ \\
\hline Q3 & 94 & $115 \cdot 7$ & 0.7 & $0 \cdot 4,1 \cdot 0$ & 0.7 & $0.4,1 \cdot 0$ \\
\hline Q4 & 88 & $202 \cdot 6$ & 0.6 & $0.4,0.9$ & 0.7 & $0 \cdot 4,1 \cdot 0$ \\
\hline$P$ for linear trend & & & & & & \\
\hline Vitamin $B_{1}(\mathrm{mg})$ & & & & & & \\
\hline Q1 (referent) & 136 & 0.5 & $1 \cdot 0$ & & 1.00 & \\
\hline Q2 & 83 & 0.6 & 0.8 & $0.5,1 \cdot 2$ & 0.8 & $0.5,1.2$ \\
\hline Q3 & 99 & 0.8 & $1 \cdot 0$ & $0.6,1.6$ & $1 \cdot 0$ & $0 \cdot 6,1 \cdot 7$ \\
\hline Q4 & 102 & 0.9 & $1 \cdot 6$ & $0 \cdot 9,2 \cdot 6$ & 1.5 & $0 \cdot 9,2 \cdot 6$ \\
\hline$P$ for linear trend & & & & & & \\
\hline Riboflavin (mg) & & & & & & \\
\hline Q1 (referent) & 132 & $0 \cdot 3$ & $1 \cdot 0$ & & $1 \cdot 0$ & \\
\hline Q2 & 95 & 0.4 & 0.6 & $0.4,0.9$ & 0.6 & $0.4,0.9$ \\
\hline Q3 & 105 & 0.5 & 0.9 & $0 \cdot 6,1 \cdot 3$ & 0.9 & $0.6,1.3$ \\
\hline Q4 & 88 & 0.7 & 0.6 & $0.4,0.9$ & 0.6 & $0.4,0.9$ \\
\hline$P$ for linear trend & & & & & & \\
\hline Vitamin C $(\mathrm{mg})$ & & & & & & \\
\hline Q1 (referent) & 132 & $58 \cdot 9$ & $1 \cdot 0$ & & $1 \cdot 0$ & \\
\hline Q2 & 93 & $83 \cdot 1$ & 0.9 & $0 \cdot 6,1 \cdot 3$ & 0.9 & $0 \cdot 6,1 \cdot 3$ \\
\hline Q3 & 105 & $112 \cdot 5$ & $1 \cdot 0$ & $0 \cdot 7,1 \cdot 4$ & $1 \cdot 0$ & $0 \cdot 7,1 \cdot 4$ \\
\hline Q4 & 90 & $151 \cdot 8$ & 0.8 & $0 \cdot 5,1 \cdot 1$ & 0.8 & $0 \cdot 6,1 \cdot 2$ \\
\hline$P$ for linear trend & & & & & & \\
\hline
\end{tabular}




\begin{tabular}{|c|c|c|c|c|c|c|}
\hline \multirow[b]{2}{*}{ Item* } & \multirow[b]{2}{*}{ No. of cases } & \multirow[b]{2}{*}{ Median daily intake in controls } & \multicolumn{2}{|c|}{ Model It } & \multicolumn{2}{|c|}{ Model II } \\
\hline & & & OR & $95 \% \mathrm{Cl}$ & OR & $95 \% \mathrm{Cl}$ \\
\hline \multicolumn{7}{|l|}{$\mathrm{Fe}(\mathrm{mg})$} \\
\hline Q1 (referent) & 146 & $5 \cdot 3$ & $1 \cdot 0$ & & $1 \cdot 0$ & \\
\hline Q2 & 77 & $6 \cdot 7$ & 0.8 & $0 \cdot 6,1 \cdot 2$ & $0 \cdot 8$ & $0 \cdot 6,1 \cdot 2$ \\
\hline Q3 & 87 & $8 \cdot 0$ & 0.8 & $0 \cdot 5,1 \cdot 2$ & $0 \cdot 8$ & $0 \cdot 5,1 \cdot 2$ \\
\hline Q4 & 110 & $12 \cdot 2$ & 0.9 & $0 \cdot 6,1 \cdot 2$ & 0.9 & $0 \cdot 6,1 \cdot 3$ \\
\hline$P$ for linear trend & & & \multicolumn{2}{|c|}{0.29} & \multicolumn{2}{|c|}{0.27} \\
\hline
\end{tabular}

DBI_LBS, Dietary Balance Index, low bound score.

${ }^{*}$ Cut-offs based on intakes among control participants.

†Adjusted for total meat consumption, protein, age, BMI, waist circumference and diastolic blood pressure.

¥Further adjusted for energy, fat, expenditure for food and pregnancy times in lifetime besides other confounders in model I.

§Q1, 1st quartile; Q2, 2nd quartile; Q3, 3rd quartile; Q4, 4th quartile.

IIMicrograms of retinol equivalents, the sum of vitamin A intake from animal foods and beta-carotene from plant sources.

- Vitamin A from animal foods.

assessed by the Chinese Food Guide Pagoda ${ }^{(14)}$ and only a very low proportion of subjects have sufficient nutrient intakes as assessed by the Chinese Dietary Reference Intakes ${ }^{(19)}$; the same thing happened even in the controls. Furthermore, the severity of under-intake was greater for the cases compared with the controls. The food-based components of the DBI_LBS - i.e. cereals, vegetables and fruits, beans and dairy, animal foods - are the main food components of daily diet and also the main sources of total energy for Chinese women. So it may indicate that diet quality and total energy intake have a strong impact on the development of anaemia.

In the present study, the total animal food consumption of the anaemic women was significantly lower than that of the controls. Although not statistically significant, the proportion of Fe from animal foods in anaemic women was slightly lower than that in controls. This indicates that the amount of animal food consumption and the Fe form in food can affect Fe absorption and utilization. Muscle tissue is a strong enhancer of non-haem Fe absorption and Fe bioavailability strongly influences non-haem Fe absorption from single meals ${ }^{(20)}$. Lyle et al. ${ }^{(21)}$ showed that meat consumption was superior to Fe supplementation for maintaining $\mathrm{Hb}$ and serum ferritin concentrations in college women. Patterson et al. ${ }^{(22)}$ reported that the form of $\mathrm{Fe}$ and the role of enhancers and inhibitors of $\mathrm{Fe}$ absorption may be more important than total Fe intake in determining Fe status.

\section{Fe intake and its relationship with anaemia}

Although the absolute quantity of Fe intake is thought to play a central role in the aetiology of anaemia, the present analyses found that the amount of dietary Fe intake had no relationship with anaemia in the studied population. One possible reason may be that Fe bioavailability was different between the two groups. There is a very large difference in Fe absorptivity for different Fe forms. Haem Fe represents $10-15 \%$ of dietary Fe intake in meat-rich diets but may contribute $10-40 \%$ of the total absorbed Fe. However, non-haem Fe contained in plant foods has a low absorptivity ${ }^{(19)}$. In the present study, the main source of Fe was from plant foods. So we suggest that the cause of anaemia was not the difference in non-haem Fe bioavailability in plant foods itself between the two groups, but the difference in enhancers of Fe bioavailability, since the low absorptivity of non-haem Fe in plant foods would be more influenced by enhancers of Fe compared with haem Fe. Another hypothesis could be that the difference in Fe intake between the two groups was not large enough to get a statistically significant difference. The third possible reason might be that the sample size was not large enough to find the real difference. This result suggests that individual $\mathrm{Fe}$ intake may not be independently associated with anaemia and inadequate absorption of Fe may be the true impact factor on anaemia. Further research work needs to be done on this issue, particularly for elderly Chinese women.

\section{Limitations and furtber study}

Several possible limitations of the study warrant consideration. First, as in other case-control studies, there was a potential for methodological bias, such as a combination of selective participation or recall of past diet. Second, we did not distinguish the anaemia of chronic disease from nutritional anaemia by credible biochemical indicators. Fortunately, we excluded those anaemic women who suffered serious diagnosed disease or whose $\mathrm{Hb}$ value was $<90 \mathrm{~g} / \mathrm{l}$, considering they had a greater possibility of suffering anaemia of chronic disease. It should be noted that a minor population of cases had suffered certain chronic diseases according to our health questionnaire. The relationship between anaemia and dietary factors would be more distinct if we excluded all chronic disease sufferers. We will try to seek the effect of chronic disease on anaemia by detecting blood biochemical indices and developing other relevant surveys in further study. Third, owing to the limitation of the food composition table of China, we could not calculate the dietary intake of folic acid and vitamin $\mathrm{B}_{12}$ and assess their nutritional status. If possible, we will try to detect the 
folic acid and vitamin $\mathrm{B}_{12}$ in Chinese food and then analyse the total potential related dietary factors for anaemia, especially on nutritional anaemia.

\section{Conclusion}

Undernutrition, which was positively associated with anaemia, was an important risk factor for anaemia, particularly for Chinese elderly women in undeveloped area. For vitamin A (RE), there appeared to be a significantly negative relationship with anaemia risk. Individual Fe intake was not found to have an independent association with anaemia.

\section{Acknowledgements}

Sources of funding: The study was funded by the Nestlé Foundation. Conflicts of interest: None. Authorship contributions: J.Z. contributed to the conception and design of the study; J.L. contributed to the field work management; L.M., C.W., Q.M. and L.L. collected the data; L.M. analysed the data and drafted the paper; J.Z. commented upon and revised drafts. All authors gave their approval to the final version submitted for publications. Acknowledgements: We would like to thank the participating regional centres for disease control and prevention in Guangxi Province, including Tiandeng and Bama Centers, for their support in the data collection. We also thank all the subjects enrolled in this project.

\section{References}

1. Ania BJ, Suman VJ, Fairbanks VF, Rademacher DM \& Melton LJ III (1997) Incidence of anemia in older people: an epidemiologic study in a well defined population. J Am Geriatr Soc 45, 825-831.

2. Semba RD, Shah N, Klein RS, Mayer KH, Schuman P \& Vlahov D; Human Immunodeficiency Virus Epidemiology Research Study Group (2002) Prevalence and cumulative incidence of and risk factors for anemia in a multicenter cohort study of human immunodeficiency virus-infected and -uninfected women. Clin Infect Dis 34, 260-266.

3. Nissenson AR, Goodnough LT \& Dubois RW (2003) Anemia: not just an innocent bystander? Arch Intern Med 163, 1400-1404

4. Caro JJ, Salas M, Ward A \& Goss G (2001) Anemia as an independent prognostic factor for survival in patients with cancer: a systemic, quantitative review. Cancer 91, 2214-2221.
5. Mozaffarian D, Nye R \& Levy WC (2003) Anemia predicts mortality in severe heart failure: the Prospective Randomized Amlodipine Survival Evaluation (PRAISE). J Am Coll Cardiol 41, 1933-1939.

6. Ania BJ, Suman VJ, Fairbanks VF \& Melton LJ III (1994) Prevalence of anemia in medical practice: community versus referral patients. Mayo Clin Proc 69, 730-735.

7. Salive ME, Cornoni-Huntley J, Guralnik JM, Phillips CL, Wallace RB, Ostfeld AM \& Cohen HJ (1992) Anemia and hemoglobin levels in older persons: relationship with age, gender, and health status. J Am Geriatr Soc 40, 489-496.

8. Daly MP (1989) Anemia in the elderly. Am Fam Physician 39, 129-136.

9. World Health Organization (1968) Nutritional Anaemias. Report of a WHO Scientific Group. WHO Technical Report Series no. 405. Geneva: WHO.

10. Wang LD (2005) Chinese Nutrition and Health Survey 2002. Beijing: People's Health Publishing House.

11. Smith DL (2000) Anemia in the elderly. Am Fam Physician 62, 1565-1572.

12. Institute of Nutrition and Food Hygiene, Chinese Academy of Preventive Medicine (1991) Food Composition Table. Beijing: People's Health Publishing House.

13. He YN, Zhai FY \& Ge KY (2005) Establishing Chinese Dietary Balance Index. J Hyg Res 34, 208-211.

14. Expert Committee of the Chinese Dietary Guidelines (1999) Dietary Guidelines in China. Beijing: China Procuratorial Press.

15. Gamble MV, Palafox NA, Dancheck B, Ricks MO, Briand K \& Semba RD (2004) Relationship of vitamin A deficiency, iron deficiency, and inflammation to anemia among preschool children in the Republic of the Marshall Islands. Eur J Clin Nutr 58, 1396-1401.

16. Lin LM, Song XF, Liu YL, Ma GF, Tan ZW, Jiang JX, Liu M, Liu CY \& Wang I (2003) Relationship between vitamin A deficiency and anemia for Chinese children. Chin J Child Health Care 4, 242-244.

17. Dreyfuss ML, Stoltzfus RJ, Shrestha JB, Pradhan EK, LeClerq SC, Khatry SK, Shrestha SR, Katz J, Albonico M \& West KP Jr (2002) Hookworms, malaria and vitamin A deficiency contribute to anemia and iron deficiency among pregnant women in the plains of Nepal. J Nutr 130, 2527-2536.

18. Semba RD \& Bloem MW (2002) The anemia of vitamin A deficiency: epidemiology and pathogenesis. Eur J Clin Nutr 56, 271-281.

19. Chinese Academy of Nutrition (2000) Chinese Dietary Reference Intake. Beijing: Chinese Light Industry Publishing House.

20. Hurrell RF (1997) Bioavailability of iron. Eur J Clin Nutr $\mathbf{5 1}$, Suppl. 1, S4-S8.

21. Lyle RM, Weaver CM, Sedlock DA, Rajaram S, Martin B \& Melby CL (1992) Iron status in exercising women: the effect of oral iron therapy vs increased consumption of muscle foods. Am J Clin Nutr 56, 1049-1055.

22. Patterson AJ, Brown WJ \& Roberts DCK (1998) Development, prevention and treatment of iron deficiency in women. Nutr Res 18, 489-502. 